\title{
Re-contextualizing Opportunity as artefact Signalling for Entrepreneurial Action
}

22 May 2021

\section{Dr David Leong}

University of Canberra, University of Canberra, Bruce ACT 2617 Australia

\section{Keywords: \\ Entrepreneurship \\ Opportunity}

Signalling theory

\begin{abstract}
This paper reviews the concept of entrepreneurial actions arising from the opportunities using signalling theory as the building blocks to discuss the process from perception, recognition to enactment. By adopting a dynamic approach to study how entrepreneurs see opportunities, particularly the initial opportunities beliefs, change over time. The perceived potentialities from the signals arising from opportunities also change. Strength of the initial opportunity beliefs, morph-ability of opportunities, frequency of opportunity appearances, multiple interpretations of opportunity, latency of opportunity, observability (intensity, visibility, strength and clarity), distortions of opportunity and false opportunity are topics that are scarcely addressed in entrepreneurial opportunities studies. We argue that the signalling effects open new veins of inquiry related to opportunity and entrepreneurial actions. Instead of seeing opportunity from either the discovery or creation approaches, opportunity should be viewed as opportunity-asartefact with embedded perceived potentialities.
\end{abstract}

\section{INTRODUCTION}

This paper builds on the existing empirical and theoretical researches in the area of entrepreneurial opportunity identification, recognition and enactment. Exploring from the perspectives of personality and behavioural traits like alertness to tapping into the socio-material network in the entrepreneurial environment, this paper develops a theoretical model based on opportunity-as-artefact premising on the signalling theory to deepen the elaboration on the conceptualization of opportunity. By conceptualizing opportunity as an artefact is about creating the artificial with the science of design (Simon, 1996). "Historically and traditionally, it has been the task of the science disciplines to teach about natural things: how they are and how they work. It has been the task of engineering schools to teach about artificial things: how to make artifacts that have desired properties and how to design" (Simon, 1996: 111). According to Simon, the science of artificial phenomena is situated in a state of dissolving and vanishing in the "thin interface between natural laws within it and the natural laws without" (Simon, 1996: 111). Opportunity appearances exhibit these phenomenon, appearing, dissolving and morphing into other opportunistic forms, with newer information and knowledges as entrepreneurs move into different phases of the journey. Opportunity belief morphs to a greater or lesser degree and rarely stays static from its nascent stage to maturity. This is the main contention of this paper and as opportunity evolves, opportunity belief morphs and signals entrepreneurs to devise means in their exploitation. 
Entrepreneurs operate under conditions of uncertainty constantly in their search for opportunities. Identifying opportunities under uncertain conditions while interacting with other heterogenous agents from competitors, imitators, suppliers to clients add to the complexity in entrepreneurship. They have to bring on a certain level of awareness and alertness, despite the noise and distractions from the market to pick the correct signal to act accordingly. Opportunities arise essentially from information asymmetry. The challenges for entrepreneurs is exacerbated potentially by information asymmetry between them and the resource holders and environment (Quy \& Huy, 2016). Fundamentally, signalling theory is featuring on the reduction of information asymmetry (Spence, 2002). Information affects the recognition, evaluation and development of the opportunity (Ardichvili et al., 2003). Signalling, in retrospect, impacts the informational structure of markets, triggering entrepreneurs to specific actions by the lure of the profit. "Major factors that influence this core process of opportunity recognition and development leading to business formation include: 1. entrepreneurial alertness; 2. information asymmetry and prior knowledge; 3. social networks; 4. personality traits, including optimism and self-efficacy, and creativity; and 5. type of opportunity itself" (Ardichvili et al., 2003: 106).

Entrepreneurial opportunity in current extant literatures are mostly situated in static state, waiting to be discovered (Shane, 2000) or are seen from the creation approach (Alvarez \& Barney, 2007). Since (Shane \& Venkataraman, 2000), multiple veins of researches and conceptual frameworks on opportunity emerge. Discovery, creation and actualization (Ramoglou \& Tsang, 2016) are prevailing concepts that framed opportunity researches. "And yet, nearly a century since the unveiling of Knightian uncertainty as a precursor to profit-making, the identification, description, and operationalization of uncertainty as a construct continue to exhibit conflicting definitions, tautological measures, and unwitting conflation with more precise constructs along the spectrum of ignorance and unknowingness." (Townsend et al., 2018: 659). (Shane \& Venkataraman, 2000) raise a pertinent and critical question- why entrepreneurial opportunities exist and why some people, and not others, discover and exploit those opportunities. It is the subsequent set of adopted entrepreneurial activities in the pursuit of the opportunity that is the larger question. What triggers entrepreneurs into exploitation of entrepreneurial opportunities?

\section{OPPORTUNITY, RECONTEXUALISED}

Uncertainty-bearing, resource-coordinating and self-organizing entrepreneurs need to be perceptive and particularly alert to the presence of opportunities, real or artificial. The recognition, evaluation and development constitute the opportunity triadic-action pack. "He cannot, except by understanding, assign to each of $n$ factors its role in producing the effect P. Understanding is in the realm of history the equivalent, as it were, of quantitative analysis and measurement" (Von Mises, 1949: 56). To understand the temporal dynamics of opportunities, how opportunities appear whether real or artificial, in the entrepreneurial process needs to be clarified.

The triadic recognition-evaluation-development sequence moving from exploration to exploitation in the entrepreneurial process is a repetitive and iterative process. It is as much behavioural as it is habitual to the entrepreneurs.

“... those who begin at the bottom never manage to lift their heads high enough to be seen by opportunity, so they remain at the bottom. It should be remembered, also, that the outlook from the bottom is not so very bright or encouraging. It has a tendency to kill off ambition. We call it "getting into a rut," which means that we accept our fate because we form the habit of daily routine, a habit that finally becomes so strong we cease to try to throw it off. And that is another reason why it pays to start one or two steps above the bottom. By so doing one forms the habit of looking around, of observing how others get ahead, of seeing opportunity, and of embracing it without hesitation." (Hill, 2011: 88)

From the process perspective, the entrepreneurial venturing model is constantly evolving and changing over time based on concurrent interplay of forces for stability as the system moves far-from-equilibrium (Lichtenstein, 2009). "This punctuated equilibrium model of (entrepreneurial) organization evolution focuses on both continuities and discontinuities in the lives of (entrepreneurial) organizations and assigns a vital role for greater understanding of organizational periods, environmental discontinuities, the impact of (entrepreneurial) organizational history on current behaviour." (Tushman \& Romanelli, 1985: 171, emphasis added). The changes happen because of discontinuities from chaos and disruptive events like financial crisis or global pandemic. Or it can be discontinuities arising from the emergence of opportunities - like a sudden surge demand for nickel for EV batteries in electric cars or for semiconductor parts when factories are damaged from earthquakes. When opportunities arise in such occasions, how are they seen and interpreted? 
The notion that entrepreneurial opportunities pre-exist or exist in some space, at a time "out there" waiting for discovery (Shane \& Venkataraman, 2000) by some alert entrepreneurs (Kirzner, 1980) is a conceptual definition of opportunity. The discovery approach discusses opportunity as object of physical observability out in the world awaiting for discovery. The creation approach is the other equally established conceptual definition of opportunity which argues that opportunities are created endogenously through the entrepreneurial agency (S. Sarasvathy, 2014). "The creation view of opportunities suggests that opportunities are not separate from the individuals that form them since opportunities are the result of the entrepreneurial process in a cycle of interactive action and change among the entrepreneur, interested others, and their immediate environment" (Alvarez et al., 2014: 229). The entrepreneurial process's path creation is premised and dependent on the process on improvisations and learning. Opportunity emergence is a function of the actions of the entrepreneurs. Implicit in this process is the exploitation of the opportunity. The pathway will not emerge until after the enactment or after the decision to act. In (Ramoglou \& Tsang, 2016: 410), actualization approach theorizes "opportunities as unactualized propensities".

“... propensities may remain unactualized because powers may not be triggered, and when triggered they need not be evident either because countervailing factors may constrain their empirical realization, or because additional enabling factors might be absent. In such occasions unobservable tendencies are said to operate transfactually. " (Ramoglou \& Tsang, 2015: 412)

The larger question is- is the observable opportunity real or artificial? Ramoglou asserts on the misuse of realism in the study of opportunity in entrepreneurship (Ramoglou, S, 2013). So is opportunity existing "in the mind" or "out of the mind" to exist objectively and be observable? Is it an "in the mind" or "out of mind" entrepreneurial envisaging? This paper construes opportunity as artefact. The opportunity-as-artefact can be observable or created. They are still subjected to the cognitive processing "in the mind". The "cognitive limitations on our rationality allow us to build artifacts that achieve only local optima at best; yet, our artifacts can endure over time by learning to adapt to contingencies and sometimes even exploit those contingencies for their own survival and prosperity." (Sarasvathy, 2003: 205)

\section{Opportunity-as-artefact}

"An artifact can be thought of as a meeting point an "interface" in today's terms between an "inner" environment, the substance and organization of the artifact itself, and an "outer" environment, the surroundings in which it operates" (Simon, 1996: 6). In the same vein, the observable opportunity in the "outer" environment, the surroundings in which it operates construct an artefact that interfaces with the "inner" environment i.e. "in the mind". From this perspective, opportunity-as-artefact is constructed and situated at the interface between the "inner environment" and "outer environment, between the entrepreneur and the environment (Berglund et al., 2020). Nexus is another such described artefact as the boundary in the "individual-opportunity nexus" (Shane \& Eckhardt, 2003). By such conceptualization, we hope to construct an alternative account of opportunity, be they discovered, created, co-created (Garud et al., 2014), by bricolage or effectuation (Welter et al., 2016), which are pathways to opportunity formation to overcome. We hope to overcome the problematic grip on the emergence of opportunities and how they drive action. Opportunity-as-artefact should therefore be seen as constantly evolving with time, interlacing with new knowledge and information. Opportunity-as-artefact is in a process of coming-into-being, and morphing. It is in a state of projection "in the mind" of the entrepreneurs.

From the practice perspective, the artefacts are the mediating objects in the boundary between the entrepreneurs and the external environment instantiating into the abstract opportunity-as-artefact. "The abstract opportunity-as-artifact is then iteratively developed in an entrepreneurial design process" (Berglund \& Glaser, 2021: 5).

"In this context, an opportunity epitomizes the symbolic aspect of the interaction between entrepreneurs and their environments. It can be regarded as an evolving blueprint for action, synthesizing the entrepreneur's sense of, expectations about, and aspirations for the future, and can help us understand what the entrepreneur does at every step of the way from within the worldview that the entrepreneur holds." (Dimov, 2011: 62-63)

Studying opportunity-as-artefact is about recasting the way opportunity is viewed through the various theoretical lens and frames into the worldview that the entrepreneurs hold. This is crucial as it raises a deeper question on the purpose of researching on entrepreneurship and that relationship with actual entrepreneurial practice and action. Opportunity is still a core and central construct in entrepreneurial research. It is a hard grip on the concept of opportunity when time is taken into consideration. The time of discovery and place of discovery

Corresponding author: David Leong, email address: u3221961@uni.canberra.edu.au. 
of the opportunity become relevant. The entrepreneurs' initial opportunity beliefs will not stay the same throughout the process. They are likely to morph into different beliefs at different phases with changing circumstances and new knowledge. The role of time throughout the opportunity formation process is crucial as most extant literatures treat non-evolving state of the opportunities.

This is the paradox and a major piece of the puzzle in the definition of opportunity, from an ontological and epistemological perspectives with time embedded in the construct. When is opportunity to be deemed as opportunity? Is it when it can come to a stage of actualization of profits or actualization of a profitable venture? Or before? If the opportunity enacted led to a failure with wasted motion, as a false positive, does it still constitute as an opportunity. Or when the initial opportunity belief turns out to be a false positive, is it still deemed as opportunity at all?

It is "very difficult to establish since whatever profitable venture is actualized will in fact have depended on an unknown set of complexly interacting empirically unobservable generative mechanisms." (Henrik Berglund \& Korsgaard, 2017). The complexity of emergent mechanism with varied open systems and "intervening levels of reality" (Bhaskar, 2013: 109) at work makes it almost improbable to ascertain ex-ante if the opportunity is real or false.
"Now it is characteristic of open systems that two or more mechanisms, perhaps of radically different kinds, combine to produce effects; so that because we do not know ex ante which mechanisms will actually be at work (and perhaps have no knowledge of their mode of articulation) events are not deductively predictable. Most events in open systems must thus be regarded as 'conjunctures'." (Bhaskar, 2013: 109)

Thus, it is not feasible to argue on the construct of whether opportunities are discovered, created or actualized. At the moment of responding to the lure of profits or imagined state of a profitable venture, it is an ex ante moment. It is rather more practical to dwell in the "seduction" of the opportunities-as-artefact and how they spur actions evidenced through their effects on the entrepreneurs. How do opportunities influence and instigate entrepreneurial actions? "While all views relate opportunities to the need to recognize the possibility of a different future, the term 'opportunity' is subject to different academic practices, each with distinct observational stance and focal points." (Dimov, 2018: 7).

To summarize, the focal point is to treat opportunity-as-artefact with its potentialities embedded within it. It is action that finally matters in entrepreneurial venturing. Without enactment, the stay of situation remains. "For the entrepreneur, the action is a practical mode of coping with the vicissitudes of existence, subject to chance and the contingency of time" (Dimov, 2018: 2). Action that follows is a response to the potentialities perceived in the opportunities. Entrepreneurs pursue opportunities to capture the potentialities and to extract value and profits. The potentialities that is observed must be cognitively recognized "in the mind". To explore the possibilities, under conditions of uncertainty, is to chase the opportunity in a self-organized manner with successive actions and iterative activities until the perceived potentialities cease to exist.

\section{SIGNALLING THEORY AND ENTREPRENEURSHIP}

Fundamentally, signalling theory is concerned with the reduction of information symmetry between signallers and the receivers (Spence, 2002). Or described in biological signalling "where "signalers" and "recipients" are cells within a same body, or where an individual may receive its own "signal" later in time (such as bees' scent-marks on flower)" (Hasson, 1997: 140). Researchers have applied signalling theory to explain the influence of information asymmetry in a wide contexts from HR, IPOs to management studies (Connelly et al., 2011). In other examples, the signals may come from accounting events. The accounting events from derivatives and other financial instruments transactions are accounting information capable to signal the risks for hedging (Rossieta, 2009). Accounting information signals firm's performance.

"Accounting information provided in the financial statements is considered as one of the most prominent and reliable monitoring system. In the light of these circumstances, managers try to provide signal of firm's performance via financial statements, both directly (i.e., via narrative disclosures) and indirectly (i.e., via accounting numbers), so that firm's value would be more consistent with its performance." (Rossieta, 2009: 20)

In the same vein, this paper argues that entrepreneurial opportunity signals potentialities like how accounting information signals risks and firm's performance. In here, the discussion is based on opportunity-as-artefact as the 
signaller and the entrepreneur as the receiver. The signal has a positive specific effect on the receiver and influences the behaviour usually occurring through changing their "information state" and subsequent strategies (Hasson, 1997).

To spur academic exploration along signalling theory's relevance to entrepreneurial opportunity, some key constructs in signalling will be elaborated. Signalling effects can be expressed as activators and pointers. Activators are signals that elicit receivers' responses regardless of environmental factors. Pure pointers are signals that either direct or divert attention to or from other signals or cues (Hassan, 1997). In both of these descriptions, opportunity-as-artefact can act both as activators and pointers.

\section{Key considerations and constructs in signalling}

So far, most extant literatures on opportunities avoided discussion of strength of the initial opportunity beliefs,, frequency of appearance of opportunity (its observability from intensity, strength, visibility and clarity) morphability of opportunity, consistency of opportunity, distortions and noise surrounding opportunity. Signalling theory, in the context of entrepreneurship, is applicable from the angle of information asymmetry and that the opportunity-as-artefact emanates signals on the market disequilibrium and potential to arbitrage. Essentially, they are market signals. These signals are projections "in the minds" of the entrepreneurs and may be considered arbitrarily. Factors that may prevent them from being entirely perceived or understood can only be on account of the recipients' perceptibility and alertness; the constraints, or limits to the proficiency of recipients to perceive differences or even meaning in some signals, at their optimal signalling values (Hasson, 1997). Ability to perceive and to understand these signals is based on their prior experience and knowledge. In this case, the recipient is the entrepreneur. "The recipient's behavioral change usually makes sense if their information state has changed as a result of signaling" (Hasson, 1997: 153-154).

\begin{tabular}{|c|c|}
\hline Construct & Definition \\
\hline $\begin{array}{l}\text { Observability (intensity, } \\
\text { strength, clarity, visibility }\end{array}$ & $\begin{array}{l}\text { Signal visibility and observability refer to the extent to which the receivers are able } \\
\text { to notice the signal. The intensity and strength of the signal clarify the meaning of } \\
\text { the signal. To contextualize on entrepreneurial terms, opportunity-as artefact must } \\
\text { be observable by the entrepreneurs but its clarity is dependent on the intensity and } \\
\text { strength of the signal. The parameters of the opportunities or arbitrage-able deltas } \\
\text { have to be clear and obvious for any actions. The intensity and strength has direct } \\
\text { proportionality to the entrepreneurial motivation to act. The stronger the signal, } \\
\text { the greater the intention and motivation to act (Seiler, 2015). }\end{array}$ \\
\hline Fit & $\begin{array}{l}\text { Extent to which the signal is correlated with unobservable quality. To contextualize } \\
\text { on entrepreneurial terms, signal fit is whether the opportunity-as-artefact is } \\
\text { relevant to the entrepreneurs. Signals of all kinds exist in the marketplace. } \\
\text { Extant literature generally suggests a positive relationship between } \\
\text { entrepreneurial self-efficacy and entrepreneurial intention (Hsu et al., 2019), signal } \\
\text { fit or opportunity fit is a moderator. } \\
\text { "A strong perception of fit with entrepreneurship is achieved, entrepreneurial } \\
\text { intention is strongly predicted by entrepreneurial self-efficacy. In contrast, if one } \\
\text { perceives a low level of fit or no fit, entrepreneurial intention will below, regardless } \\
\text { of entrepreneurial self-efficacy" (Hsu et al., 2019: 311). }\end{array}$ \\
\hline Frequency & $\begin{array}{l}\text { Frequency is defined as the number of times the signal is observed over time. } \\
\text { Signalling effectiveness is enhanced by sending more observable signals or } \\
\text { increasing the number of signals- signal frequency (Janney \& Folta, 2003). } \\
\text { "Signals are essentially snapshots pointing to unobservable signaler quality at a } \\
\text { particular point in time. However, organizations operate in dynamic environments, } \\
\text { and information that is available to both signalers and receivers is constantly } \\
\text { changing. If signalers wish to remain differentiated, they will signal repetitively to } \\
\text { keep reducing information asymmetry. Signaling repetitively can increase the } \\
\text { effectiveness of the signaling process, especially if one uses different signals to } \\
\text { communicate the same message" (Connelly et al., 2011: 53-54). }\end{array}$ \\
\hline
\end{tabular}




\begin{tabular}{|c|c|}
\hline & $\begin{array}{l}\text { "It is argued theoretically that the attitudinal gain from advertising repetition } \\
\text { should continue to increase rather than level off when consumers fail to generate } \\
\text { cognitive responses to message arguments in earlier exposures. An experiment } \\
\text { shows that repetition continues to increase brand attitudes and purchase } \\
\text { intentions in conditions where support and counter argument production is } \\
\text { expected to be low, but that these attitudinal gains level off under conditions in } \\
\text { which a high level of such production is expected" (Batra \& Ray, 1986: 432) . } \\
\text { On entrepreneurial terms, when the opportunity appearance or emergence } \\
\text { appears in different contexts and time, frequently enough for the entrepreneurs to } \\
\text { be convinced to act. }\end{array}$ \\
\hline Consistency & $\begin{array}{l}\text { Signal consistency is defined as the similarity between multiple signals arising from } \\
\text { one source. On entrepreneurial terms, such consistency establishes a triangulation } \\
\text { effect to confirm the potentiality in the opportunity. } \\
\text { The exposure to external information, as signal, regulates the evaluation of } \\
\text { entrepreneurial opportunities and entrepreneurial action. When the signal is } \\
\text { consistent, it augurs confidence and convergence. Information as signal shapes } \\
\text { opportunity evaluation and that drives to entrepreneurial action (Autio et al., } \\
\text { 2013). }\end{array}$ \\
\hline Receiver attention & $\begin{array}{l}\text { Extent to which the receiver vigilantly scan the signalling environment. In } \\
\text { entrepreneurial terms, there are three distinct elements of alertness as comprising } \\
\text { three dimensions: (1) systematically or non-systematically scan the environment } \\
\text { and search information; (2) associate or piece together previously unconnected } \\
\text { information; and } \quad \text { (3) make evaluations and judgments about the } \\
\text { commercializability of the idea" (Tang et al., 2012: 90). }\end{array}$ \\
\hline $\begin{array}{l}\text { Receiver interpretation } \\
\text { (calibration) }\end{array}$ & $\begin{array}{l}\text { The way the signal is unpacked and decoded to be understood - translating signals } \\
\text { into perceived meaning. The sensemaking of the signal is very much associated } \\
\text { with the prior knowledge and information interlacing through "association and } \\
\text { connection, and evaluation and judgment" (Tang et al., 2012: 92) }\end{array}$ \\
\hline Distortion & $\begin{array}{l}\text { Noise that can be introduced by the signalling environment, external referents or } \\
\text { other agents causing interference in the interpretation of the signals. With noise, } \\
\text { the clarity of the signal can be impacted reducing effective interpretation. } \\
\text { With noise, in entrepreneurial terms, it causes confusion and uncertainty. }\end{array}$ \\
\hline
\end{tabular}

Adapted from Connelly, B. L., Certo, S. T., Ireland, R. D., \& Reutzel, C. R. (2011). Signaling theory: A review and assessment. Journal of Management, 37(1), 39-67. https://doi.org/10.1177/0149206310388419

\section{DISCUSSION}

The overarching problem is to find an understandable framework to discuss what is an opportunity and how that opportunity signals the entrepreneurs to action. What force impels and propels the entrepreneurs to act? The scientific realism of the imposed tension induced by energy differentials can characterise the action in the entrepreneurial act. Whether the opportunity-as-artefact is to be viewed as real and objective or artificial and subjective, the actual study should feature on what drives the entrepreneurial actions to actualization. We argue that such force is truly objective and is naturally occurring in physics, quantum physics in particular.

The final claim of this paper embraces discovery, creation, actualization and delves further to discuss how the opportunityas-artefact signals for entrepreneurial action. In the "real-or-artificial" argument, the claim that opportunity is objectively and independently existing cannot be tested until after the successful exploitation of that opportunity. According to (Eckhardt \& Ciuchta, 2008), the puzzle is this - if the opportunity is not successfully exploited, in the discovery view, it is considered not to have even existed. This stands if and only if the notion of opportunity stays the same. From our argument, opportunity-as-artefact, as originally envisaged morphs and evolves over time depending on contextual conditions. This same opportunity-as-artefact's signal-eliciting capacity drive entrepreneurial action throughout the journey. The signal either acts as pointer or activator. 
The viability of initially envisaged opportunity, the initial opportunity belief, cannot be known ex-ante. In the same way, the creation approach where the opportunity is dependent on the entrepreneurs as agencies to act and to create them cannot be known ex-ante as well. The opportunity can be seen as artificial or constructed and comes into existence through the improvisations, efforts and exertions of the entrepreneurs. The argument should not be purely pivoting on the philosophical position and definition of opportunity but how that opportunities, through the imposed tension induced by the energy differentials drives actions. This processual description of how this force acts is therefore more important in entrepreneurial research. The insight of a path-dependent opportunity formation and transformation as an artefact will illuminate and direct the entrepreneurial pathway development. This also gives clarity to the dynamical nature of opportunity-as-artefact because they change and transform along the journey spurring entrepreneurs to action at each phase.

This is the main contention of this paper.

\section{Relevance of signalling theory}

Entrepreneurs in the entrepreneurial journey are mostly and variously in states of "analysing a situation as a whole, of thinking at several different levels at once, recognizing clues, piecing together diverse bits of information and assessing the likely outcomes of various courses of action" (Bhaskar, 2013: 109). Signalling theory is therefore useful for describing the behaviour of the entrepreneurs as they become the receivers of signals "from a market with incomplete and asymmetrically located information." (Spence, 2002: 434). The signal points to a tension gradient - of opportunity and it is in this phase of opportunity recognition, of its potential for exploitation that emergent self-organization occurs. This tension is the catalyst that drives the behavioural actions of the entrepreneurs. The catalytic effect "initiates a dynamic state that leads to emergence and order creation." (Lichtenstein, 2009: 2). The actions taken is internally driven arising from the signalling effect.

The opportunity-as-artefact is a construct "in the minds" of the entrepreneurs after recognizing the signals, piecing together diverse information for specific actions. This insight deals with both the issue of locality and contingency (Sarasvathy, 2003). "Locality here refers to the fact that cognitive limitations on our rationality allow us to build artifacts that achieve only local optima at best" (Sarasvathy, 2003: 205). The opportunity-as-artefact presents the potentiality from a perceived tension/ gradient perspective. The entrepreneurs learn to adapt to the situational contingencies and to work on the exploitation of those contingencies for their profits and derivation of values. In a way, the opportunity-as-artefact is the signaller cueing the entrepreneurs on the prospect of the venture. The informational asymmetries or the informational aspects of market structure are the signals/ cues. In short, the role of signalling is a call to action to resolve information asymmetries (Connelly et al., 2011).

\section{A model with signalling, potentiality, dissipation}

Opportunity-as-artefact is therefore an artificial construct that exists "in the mind" of the entrepreneur interpreting signals from the opportunity-as-artefact. The perception arises from the asymmetrical information from the market which forms the signal. Entrepreneurs therefore are constantly scanning and interpreting the signals in the face of uncertainty in their pursuit of opportunities. The force that eventually draws the entrepreneurs to action in the pursuit of the opportunities is energized by an imposed tension induced by energy differentials. The emergence of dissipative structures instigated by the imposed energy differential induces the actions (Lichtenstein, 2009).

Embedded within the opportunity-as-artefact is the perceived potentiality. This potentiality is expressed as a tension. McKelvey's definition of tension is energy differential arising from "(1) rapid phase transitions caused by adaptive tensions and (2) coevolutionary (positive feedback) processes set in motion by seemingly inconsequential instigating events" (McKelvey, 2004: 319). Entrepreneurial venturing includes uncovering such tensions and looking at means to bring these tension to rest by extracting value from the process of dissipation. In short, the perceived energy gradients are waiting to be dissipated by alert entrepreneurs who will use all creative means to achieve the dissipation (Leong, 2021). Opportunity-asartefact must elicits signal fit and occurring with sufficient frequency for entrepreneurs to be persuaded to eventually act. The signal elicited by the opportunity-as-artefact must be visibly recognized with certain strength and intensity for entrepreneurs to organize a process of dissipation to derive profits and value through those acts. Opportunities can be viewed in many ways:

'For example, while some have viewed opportunity as something identified in a moment of insight that is the result of accidental discovery, others view the opportunity-related process as taking place over time, as the result of a systematic search or as enacted and constructed in the present. Some view it is a cognitive process that can involve mental simulation and counterfactual thinking, 
heuristics based logic, or maybe an effectuation process of forming, shaping, creating, or enacting an opportunity that emerges from within the entrepreneur. Similarly the opportunity-related process has been viewed as a creative process, involving creativity, or even as a special case of problem solving.' (Hansen et al., 2011, p. 285)

Whatever perspectives that are used to recognize, discover, identify, or create opportunities, the key to entrepreneurs is to recognize the tension in the potentiality. 'The sifting and sorting and processing of an opportunity's potential plays out on a patently micro-level scale where a priori uncertainties cannot be hedged in advance of the entrepreneur taking action.' (Hansen et al., 2011, p. 36) Uncertainty is prevalent in all stages of the entrepreneurial venture setting to a larger or lesser degree as it is pervasive in entrepreneurial settings (Leong, 2021).

Entrepreneurial venturing involves constant seeking of opportunities and dissipating the gradients through gradientmanipulation mechanism (Leong, 2021). The entrepreneur will adopt exploitative strategies and actions to maintain these dissipative structures in the face of a fluctuating physical environment which is in a state of disequilibrium. In the dynamic dissipative systems, finding the means to effectively dissipate the potential gradients to profitable ends are very much part of profit extraction from the market. Entrepreneurial ventures explore known and novel means to find tensions/ potentialities in the market. They look out for signals particularly information asymmetry to capitalize and to exploit.

\section{CONCLUSION}

There is substantial work to be done as entrepreneurship scholars examine the contribution of entrepreneurship basing on scientific theories and metaphors to explain entrepreneurial actions, process and its boundary conditions. To that end, the understanding of the opportunities formation and the opportunity evolution process must move beyond a view that has not been helpful in illuminating entrepreneurship's unique contribution to create "every form of convenience that make life more pleasant" (Hill, 2011: 38).

"We who desire to accumulate riches, should remember the real leaders of the world always have been men who harnessed, and put into practical use, the intangible, unseen forces of unborn opportunity, and have converted those forces, [or impulses of thought], into sky-scrapers, cities, factories, airplanes, automobiles, and every form of convenience that makes life more pleasant." (Hill, 2011: 38)

This more illuminating view will be to incorporate the actions, processes, signals and the force that acts on the opportunities. The entrepreneurs interpret these signals arising from the opportunities through their perceived potentialities and by the strength of their belief, they will apply efforts to act on these opportunities. Opportunity may come through with weak signalling that may not immediately trigger actions. The latency of the opportunity is not immediately obvious and it may emerge at various times at different settings and space to motivate entrepreneurs to pursue the opportunity. The "perception and pursuit of opportunity is fundamentally idiosyncratic to each entrepreneur, the success of an entrepreneurial endeavour is constrained by the objective conditions of opportunity" (Renko et al., 2012: 1233)

Again, not every opportunity will be recognized with the same clarity and with such strong belief. They even may come disguised in the form of misfortune or temporary defeat. We argue that the opportunity-as-artefact morphs along the entrepreneurial process and can become quite different from the initial opportunity belief as "in nascent entrepreneurial process where the changes that occur to beliefs associated with continuing evaluation of the opportunity and related learning" (McCann \& Vroom, 2015: 612, emphasis added).

"When the opportunity came, it appeared in a different form, and from a different direction ... That is one of the tricks of opportunity. It has a sly habit of slipping in by the back door, and often it comes disguised in the form of misfortune, or temporary defeat. Perhaps this is why so many fail to recognize opportunity." (Hill, 2011: 21)

"The "depression" was a blessing in disguise. It reduced the whole world to a new starting point that gives everyone a new opportunity." (Hill, 2011: 216)

Sometimes, it may take a few appearances of the opportunity under various conditions and at varying times to convince the entrepreneurs that enactment is worth the effort. It must be noted that each of these opportunity-as-artefact that appears are independent but they conjure similar impression on the entrepreneurs. The frequency of their appearances 
signal a certain potentialities that the entrepreneurs would choose to capitalize on. The observability of that opportunity in terms of its signal intensity, visibility, frequency, strength and clarity become critical to tilt the balance in favour of purposeful actions. Strong signals are likely to compel entrepreneurs to enact with such consuming obsession and burning desire to actualize the end goal.

“... waiting his opportunity to spoil one's chances of success. Most of us go through life as failures, because we are waiting for the "time to be right" to start doing something worthwhile. Do not wait. The time will never be "just right." Start where you stand, and work with whatever tools you may have at your command, and better tools will be found as you go along." (Hill, 2011: 129)

The entrepreneurial opportunity is fundamentally still core in entrepreneurship research. With many notable challenges on its demonstrated utility, the current concepts of discovery and creation should be deepened with more layers of definitions to include strength of the initial opportunity beliefs, morph-ability of opportunities, frequency of opportunity appearance, multiple interpretations of opportunity, latency of opportunity, observability (intensity, visibility, strength and clarity), distortion of opportunity and false opportunity. These further explorations may sharpen the theoretical precision of the opportunity-as-artefact and the persistent puzzle in the construct clarity.

By and large, the lure of profit dictates entrepreneurial action and entrepreneurial actions can be sets of activities that is self-organized through determined decisions to pursue the opportunity. "Those who reach decisions promptly and definitely, know what they want, and generally get it. The leaders in every walk of life decide quickly, and firmly. That is the major reason why they are leaders. The world has the habit of making room for the man whose words and actions show that he knows where he is going" (Hill, 2011: 157). Finally, what draws and woos the entrepreneurs? It is the signalling arising from the locality and contingency (Sarasvathy, 2003). Signalling effect is contingent on the signalling environment thus locality explaining "the importance of the signalling environment influencing boundedly rational signal recipients interpreting ambiguous signals" (Park \& Patel, 2015: 796). The contingency are the probable set of actions that are considered for the exploitation of the opportunity-as-artefact. Opportunity-as-artefact emit signals.

"Opportunity has spread its wares (signals) before you. Step up to the front, select what you want, create your plan, put the plan into action, and follow through with persistence." (Hill, 2011: 145, emphasis added)

\begin{abstract}
About The Author:
David Leong, $P h D$ started his entrepreneurial ventures early, soon after he graduated from the National University of Singapore in 1994 with a Bachelor of Business Administration degree. He has founded various ventures from corporate finance, business consultancy, design consultancy, human resources (HR), publication and technology.

David was awarded his PhD from Charisma University in 2020 and is pursuing his Doctor of Business Administration with the University of Canberra for a double doctorate. His research is in entrepreneurship and he is venturing to define "entrepreneurial energy" as the energy field spurring entrepreneurial actions in the light of complex science and quantum science. His other research area is in the Chinese Yijing and he draws the relatedness of Yijing with modern science in particular quantum physics.

\author{
https://orcid.org/0000-0002-9440-3606 \\ https://nus.academia.edu/LeongDavid \\ http://straitstrades.com/david/
}

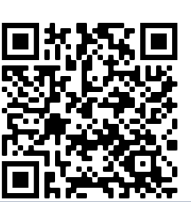




\section{REFERENCES:}

Alvarez, S. A., \& Barney, J. B. (2007). Discovery and creation: alternative theories of entrepreneurial action. Strategic Entrepreneurship Journal, 1(1-2), 11-26. https://doi.org/10.1002/sej.4

Alvarez, S. A., Barney, J. B., McBride, R., \& Wuebker, R. (2014). Realism in the study of entrepreneurship. Academy of Management Review, 39(2), 227-233. https://doi.org/10.5465/amr.2013.0244

Ardichvili, A., Cardozo, R., \& Ray, S. (2003). A theory of entrepreneurial opportunity identification and development. Journal of Business Venturing, 18(1), 105123. https://doi.org/10.1016/S0883-9026(01)00068-4

Autio, E., Dahlander, L., \& Frederiksen, L. (2013). Information Exposure, Opportunity Evaluation, and Entrepreneurial Action: An Investigation of an Online User Community. Academy of Management Journal, 56(5), 1348-1371. https://doi.org/10.5465/amj.2010.0328

Batra, R., \& Ray, M. L. (1986). Situational Effects of Advertising Repetition: The Moderating Influence of Motivation, Ability, and Opportunity to Respond. Journal of Consumer Research, 12(4), 432. https://doi.org/10.1086/208528

Benyamin Lichtenstein, A. B., \& Lichtenstein Lichtenstein, B. B. (2009). Moving far from far-from-equilibrium: Opportunity tension as the catalyst of emergence* Moving far from far-from-equilibrium: Opportunity tension as the catalyst of emergence*. Emergence: Complexity and Organization.

https://doi.org/10.emerg/10.17357.a6caf4674b89c48ca 05dd0bb8cec7b81

Berglund, H., \& Glaser, V. L. (2021). THE ARTIFACTS OF ENTREPRENEURIAL PRACTICE. Vernglaser.Com.

Berglund, Henrik, Bousfiha, M., \& Mansoori, Y. (2020). Opportunities as artifacts and entrepreneurship as design. Academy of Management Review, 45(4), 825-846. https://doi.org/10.5465/AMR.2018.0285

Berglund, Henrik, \& Korsgaard, S. (2017). Opportunities, Time, and Mechanisms in Entrepreneurship: On the Practical Irrelevance of Propensities. Academy of Management Review, 42(4), 730-733. https://doi.org/10.5465/amr.2016.0168

Bhaskar, R. (2013). A realist theory of science. Routledge.

Connelly, B. L., Certo, S. T., Ireland, R. D., \& Reutzel, C. R. (2011). Signaling theory: A review and assessment. Journal of Management, 37(1), 39-67. https://doi.org/10.1177/0149206310388419

Dimov, D. (2011). Grappling With the Unbearable Elusiveness of Entrepreneurial Opportunities. Entrepreneurship: Theory and Practice, 35(1), 57-81. https://doi.org/10.1111/j.1540-6520.2010.00423.x Dimov, D. (2018). OPPORTUNITIES, LANGUAGE, AND TIME.

Eckhardt, J. T., \& Ciuchta, M. P. (2008). Selected variation: the population-level implications of multistage selection in entrepreneurship. Strategic Entrepreneurship Journal, 2(3), 209-224. https://doi.org/10.1002/sej.48

Garud, R., Gehman, J., \& Giuliani, A. P. (2014). Contextualizing entrepreneurial innovation: A narrative perspective. Research Policy, 43(7), 1177-1188. https://doi.org/10.1016/j.respol.2014.04.015

Hansen, D. J., Shrader, R., \& Monllor, J. (2011). Defragmenting Definitions of Entrepreneurial Opportunity*. Journal of Small Business Management, 49(2), 283-304. https://doi.org/10.1111/j.1540-627X.2011.00325.x

Hill, N. (2011). Think and grow rich. Hachette UK.

Hsu, D. K., Burmeister-Lamp, K., Simmons, S. A., Foo, M.-D.,
Hong, M. C., \& Pipes, J. D. (2019). “I know I can, but I don't fit": Perceived fit, self-efficacy, and entrepreneurial intention. Journal of Business Venturing, 34(2), 311-326. https://doi.org/10.1016/j.jbusvent.2018.08.004

Janney, J. J., \& Folta, T. B. (2003). Signaling through private equity placements and its impact on the valuation of biotechnology firms. Journal of Business Venturing, 18(3), 361-380. https://doi.org/10.1016/S08839026(02)00100-3

Kirzner I.M. (1980). Perception, Opportunity and Profit. Studies in the Theory of Entrepreneurship. Chicago: The University of Chicago Press.

Leong, D. (2021). Thermodynamics Expression in Action within Entrepreneurial Process. Advance. Preprint. Https://Doi.Org/10.31124/Advance.14677758.V1.

McCann, B. T., \& Vroom, G. (2015). Opportunity evaluation and changing beliefs during the nascent entrepreneurial process. International Small Business Journal: Researching Entrepreneurship, 33(6), 612-637. https://doi.org/10.1177/0266242614544198

McKelvey, B. (2004). Toward a complexity science of entrepreneurship. Journal of Business Venturing, 19(3), 313-341. https://doi.org/10.1016/S08839026(03)00034-X

O, H. (1997). Towards a general theory of biological signaling. Journal of Theoretical Biology, 185, 139-156.

Park, H. D., \& Patel, P. C. (2015). How Does Ambiguity Influence IPO Underpricing? The Role of the Signalling Environment. Journal of Management Studies, 52(6), 796-818. https://doi.org/10.1111/joms.12132

Quy, C. Z., \& Huy, N. (2016). How Entrepreneurs Use Symbolic Management to Acquire Resources.

Ramoglou, S, . (2013). On the misuse of realism in the study of entrepreneurship. Academy of Management Review, 38(3), 463-465.

Ramoglou, S, ., \& Tsang, E, . (2015). A Realist Perspective of Entrepreneurship: Opportunities as Propensities. Academy of Management Review, 41(3), 410-434. .

Ramoglou, S., \& Tsang, E. W. K. (2016). A realist perspective of entrepreneurship: Opportunities as propensities. Academy of Management Review, 41(3), 410-434. https://doi.org/10.5465/amr.2014.0281

Renko, M., Shrader, R. C., \& Simon, M. (2012). Perception of entrepreneurial opportunity: a general framework. Management Decision, 50(7), 1233-1251. https://doi.org/10.1108/00251741211246987

Rossieta, H. (2009). Risk Signal, Financial Derivatives Transactions and The Indonesian GAPP. 10.Th Annual Asiian Academic Accounting Association Conference Proceedings, January 2010, 1490-1509.

Sarasvathy, S. (2014). Toward Causation and Effectuation : a Theoretical Shift From Inevitability To Economic Entrepreneurial. Academy of Management Journal, 26(2), 243-263.

Sarasvathy, S. D. (2003). Entrepreneurship as a science of the artificial. Journal of Economic Psychology, 24(2), 203220. https://doi.org/10.1016/S0167-4870(02)00203-9

Seiler, M. J. (2015). Do as I Say, Not as I Do: The Role of Advice versus Actions in the Decision to Strategically Default. Journal of Real Estate Research, 37(2), 191-216. https://doi.org/10.1080/10835547.2015.12091412

Shane, S. (2000). Prior Knowledge and the Discovery of Entrepreneurial Opportunities. Organization Science, 11(4), 448-469. 
Re-contextualizing Opportunity as artefact

Signalling for Entrepreneurial Action

https://doi.org/10.1287/orsc.11.4.448.14602

Shane, S., \& Eckhardt, J. (2003). The Individual-Opportunity

Nexus. In Handbook of Entrepreneurship Research (pp.

161-191). Springer-Verlag. https://doi.org/10.1007/0387-24519-7_8

Shane, S., \& Venkataraman, S. (2000). The Promise of Enterpreneurship as a Field of Research. In Source: The Academy of Management Review (Vol. 25, Issue 1).

Simon, H. A. (1996). The Sciences of the Artificial (Third edition). MIT Press, Cambridge, MA.

Spence, M. (2002). Signaling in retrospect and the informational structure of markets. American Economic Review, 92(3), 434-459. https://doi.org/10.1257/00028280260136200

Tang, J., Kacmar, K. M. (Micki), \& Busenitz, L. (2012). Entrepreneurial alertness in the pursuit of new opportunities. Journal of Business Venturing, 27(1), 7794. https://doi.org/10.1016/j.jbusvent.2010.07.001

Townsend, D. M., Hunt, R. A., McMullen, J. S., \& Sarasvathy, S. D. (2018). Uncertainty, knowledge problems, and entrepreneurial action. Academy of Management Annals, 12(2), 659-687.

https://doi.org/10.5465/annals.2016.0109

Tushman, M. L., \& Romanelli, E. (1985). Organizational evolution: A metamorphosis model of convergence and reorientation. Research in Organizational Behavior, 7, 171-222.

Von Mises, L. (1949). Human Action: a Treatise on Economics. https://doi.org/10.2307/2605641

Welter, C., Mauer, R., \& Wuebker, R. J. (2016). Bridging

Behavioral Models and Theoretical Concepts:

Effectuation and Bricolage in the Opportunity Creation Framework. Strategic Entrepreneurship Journal, 10(1), 520. https://doi.org/10.1002/sej.1215 